\title{
Opacified hydrophilic intraocular lens following DMEK
}

\author{
Minak Bhalla $\mathbb{D}^{1} \cdot$ Omar El-Haddad ${ }^{2} \cdot$ Vincenzo Maurino ${ }^{3}$
}

Received: 18 December 2019 / Revised: 9 January 2020 / Accepted: 27 March 2020 / Published online: 15 April 2020

(c) The Royal College of Ophthalmologists 2020

\section{To the Editor:}

Hydrophilic intraocular lenses' initial popularity was associated with their ease of implantation [1] but their higher incidence of posterior capsular opacity swayed surgical preference to hydrophobic lenses. Moreover, hydrophilic lenses were also found to opacifiy after secondary ocular surgeries, where an injection of gas/air had led to deposits of calcium phosphate on the optical surface in many cases [2-4].

Descemet Membrane Endothelial Keratoplasty (DMEK) is becoming the procedure of choice in patients with endothelial dystrophies due to the ease of procedure (especially where the graft is pre-cut), faster post-operative recovery and a reduced risk of graft failure [2] to its alternate Descemet Stripping Automated Endothelial Keratoplasty (DSAEK). This report highlights two cases where hydrophilic intraocular lenses have developed central corneal opacification following DMEK surgery.

Patient A is an 89-year-old gentleman who was referred for corneal graft surgery for Fuchs' Endothelial Dystrophy (FED). He previously had an uncomplicated cataract surgery where a hydrophilic Rayner RayOne ${ }^{\circledR}$ aspheric intraocular lens was inserted [5]. His visual acuity (VA) was $6 / 12$ in both eyes. He went on to have an uncomplicated DMEK. Intraoperatively, Sulphur Hexaflouride (SF6) gas was injected to ensure the graft remained in the correct position. His post-operative recovery was prolonged as he developed a high intraocular pressure (IOP). Follow-ups highlighted a notable central granular opacification (Figs. 1 and 2) however the patient remained asymptomatic. He subsequently went on to have his contralateral cataract eye

Minak Bhalla

m.bhalla@nhs.net

Royal Free Foundation Trust Hospital, London, UK

Bristol Eye Infirmary, Bristol, UK

3 Moorfields Eye Hospital, London, UK

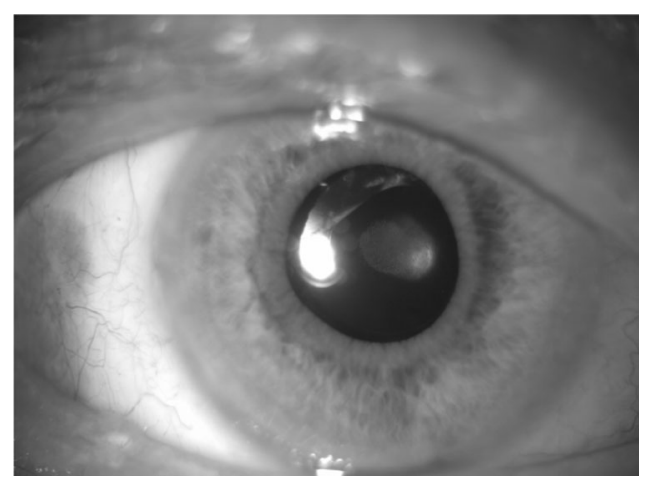

Fig. 1 Right eye of Patient A. This figure highlights a central intraocular opacification.

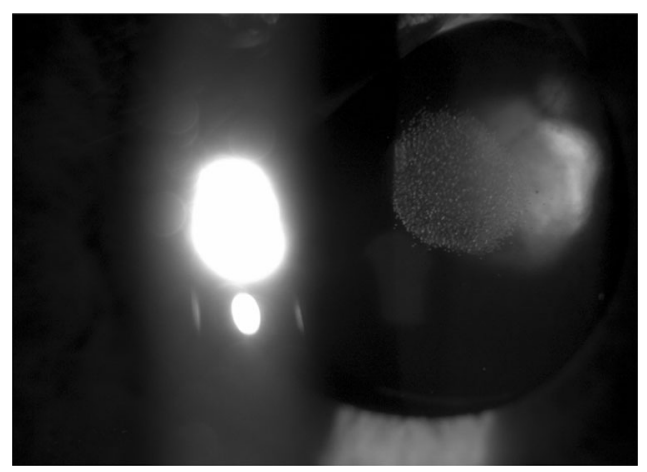

Fig. 2 Right eye of Patient A. A zoomed in image of the granular opacification on the intraocular lens of the same patient.

operated on. His VA upon discharge was 6/9 in his right eye and $6 / 6$ in his left eye and since he was asymptomatic, he was discharged.

Patient B is a 72-year-old gentleman who had an ocular history of left phacoemulsification (with no information about the type of intraocular lens inserted) and DMEK due to FED at a private hospital. His VA was $6 / 6$ in the left eye and $6 / 12$ in the right. The left graft was central and clear however he was also managed for steroid induced high IOP following the procedure on the left eye. He subsequently reached $6 / 6$ in both eyes following right eye cataract and DMEK surgery. 
Patient B re-presented with reducing left eye VA (6/36) secondary to lens opacification. Patient B underwent an uncomplicated intraocular exchange with an Alcon $^{\circledR}$ MA60AC lens. The patient's post-operative VA was $6 / 6$ and he remains under follow-up.

\section{Discussion}

Current literature has indicated that central opacification was more likely in DMEK cases that undergo re-bubbling or in patients who had sensitivity to topical steroids [5]. Prolonged high IOP was also a risk factor to the opacification as it may have impacted the optical surface of the lens.

It is theorised to be due to the break-down of the aqueous blood barrier and dehydration of the hydrophilic acrylate material causing the formation and deposition of the material. The central deposition on the visual axis is due to mechanical barrier of the iris protecting the remaining intraocular piece. Gier's et al. [4] group reported that different manufacturers have all reported similar opacifications with their respective hydrophilic intraocular lenses.

DMEK's are growing in popularity for FED patients. Informed consent for patients undergoing DMEK includes graft detachment, failure, a rise in IOP and reduced endothelial cell count. However, the cases above highlight the importance to include and subsequently discuss the possibility of lens opacifications which may lead to lens explantation. This is found especially in those patients who have had previous cataract operations where the lens type is hydrophilic or unknown.

\section{Compliance with ethical standards}

Conflict of interest The authors declare that they have no conflict of interest.

Publisher's note Springer Nature remains neutral with regard to jurisdictional claims in published maps and institutional affiliations.

\section{References}

1. Bellucci R. An introduction to intraocular lenses: material, optics, haptics, design and aberration. In: Güell JL, editors. Cataract. Basel, Switzerland: ESASO Course Series, vol. 3.2013. pp. 38-55.

2. Fellman MA, Werner L, Liu E, Stallings S, Floyd AM, van der Meulen IJE, et al. Calcification of a hydrophilic acrylic intraocular lens after Descemet-stripping endothelial keratoplasty: case report and laboratory analyses. J Cataract Refrac Surg. 2013;39:799-803.

3. Deng S, Lee B, Hammersmith K, Kuo A, Li J, Shen J, et al. Descemet membrane endothelial keratoplasty: safety and outcomes. A report by American Academy of Ophthalmology. Ophthalmology. 2017;125:295-310.

4. Giers BC, Tandogan T, Auffarth GU, Choi CY, Auerbach FN, Sel $\mathrm{S}$, et al. Hydrophilic intraocular lens opacification after posterior lamellar keratoplasty - a material analysis with special reference to optical quality assessment. BMC Ophthalmol. 2017;17:1-10.

5. Ahad MA, Darcy K, Cook SD, Tole DM. Intraocular lens opacification after descemet stripping automated endothelial keratoplasty. Cornea. 2014;13:1307-11. 